\title{
Association between TP53 codon 72 G $>$ C Polymorphism and Thyroid Carcinoma Risk: An Up-to-Date Meta-Analysis
}

\author{
Jamal Jafari Nedooshan', Mohammad Forat Yazdi², Hossein Neamatzadeh ${ }^{3}$, \\ Masoud Zare Shehneh ${ }^{4}$, Saeed Kargar ${ }^{1}$, Niloofar Seddighi ${ }^{5}$
}

${ }^{1}$ Department of General Surgery, Shahid Sadoughi University of Medical Sciences, Yazd, Iran. ${ }^{2}$ Department of Internal Medicine, Shahid Sadoughi University of Medical Sciences, Yazd, Iran. ${ }^{3}$ Mother and Newborn Health Research Center, Shahid Sadoughi University of Medical Sciences, Yazd, Iran. ${ }^{4}$ Department of Medical Genetics, International Campus, Shahid Sadoughi University of Medical Sciences, Yazd, Iran. ${ }^{5}$ Shahid Sadoughi Hospital, Shahid Sadoughi University of Medical Sciences, Yazd, Iran.

\begin{abstract}
Objective: Many published data on the association between p53 codon $72 \mathrm{G}>\mathrm{C}$ polymorphism and thyroid carcinoma risk showed inconclusive results. The present meta-analysis was designed to assess the association between $\mathrm{p} 53$ codon $72 \mathrm{G}>\mathrm{C}$ polymorphism and thyroid cancer risk. Methods: A literature search of PubMed, EMBASE, Google scholar and Web of Science databases for case-control studies examining the association between $\mathrm{p} 53$ codon $72 \mathrm{G}>\mathrm{C}$ polymorphism and thyroid cancer susceptibility up October 2016 . Odds ratios (OR) with $95 \%$ confidence intervals $(95 \% \mathrm{CI})$ were used to assess the strength of the association. Results: A total of 12 case-control studies involving 2,062 thyroid cancer patients and 3,027 controls were included. There was a significant association between the $\mathrm{p} 53$ codon $72 \mathrm{G}>\mathrm{C}$ polymorphism and thyroid cancer susceptibility in the overall populations under homozygote (CC vs. $\mathrm{GG}$ : $\mathrm{OR}=1.18,95 \% \mathrm{CI} 1.12-3.05, \mathrm{P}=0.01)$ and recessive model ( $\mathrm{CC}$ vs. $\mathrm{GC}+\mathrm{GG}$ : $\mathrm{OR}=1.73,95 \% \mathrm{CI} 1.16-2.59, \mathrm{P}=0.007)$. Subgroup analysis by ethnicity showed that there was no significant association between $\mathrm{p} 53$ codon $72 \mathrm{G}>\mathrm{C}$ polymorphism and thyroid cancer risk in Caucasians, Asians and mixed Brazilian. No significant publication bias was observed by using Begg's funnel plot and Egger's test. Conclusion: Present meta-analysis indicated that the p 53 codon $72 \mathrm{G}>\mathrm{C}$ polymorphism may be associated with thyroid cancer risk. However, more studies with large sample size are needed to further assess the associations.
\end{abstract}

Keywords: Thyroid cancer- p53- codon 72- polymorphism- meta-analysis

Asian Pac J Cancer Biol, 1 (4), 89-95

\section{Introduction}

Thyroid cancer is the most common endocrine cancer and its incidence has continuously increased in the last three decades all over the world [1]. According to the Surveillance, Epidemiology and End Results programme, thyroid cancer incidence increased 2.4-fold from 1973 to 2002 in the USA [2]. It is estimated that 62,450 new cases of thyroid cancer will occur in the USA in 2015, and 52,900 new cases of thyroid cancer developed In Europe in $2012[3,4]$

Currently, the etiology of thyroid cancer is not well understood, and exposure to radiation is the only well-known risk factor for thyroid cancer [5]. However, it is well-known that thyroid cancer is a typical human cancer
Submission Date: 08/12/2016 Acceptance Date: 11/25/2016

in which critical genes are frequently mutated. In recent years, much attention has been focused on the p53 codon $72 \mathrm{Arg} /$ Pro polymorphism with a base substitute of $\mathrm{G}$ to $\mathrm{C}$ (Arg and Pro) [6]. The p53 tumor suppressor gene is located at human chromosome $17 \mathrm{p} 13$ and encoding a 53-kDa nuclear phosphoprotein which plays an important role in cell cycle regulation, maintenance of genomic integrity, apoptosis, and challenge of environmental insults $[7,8]$. Growing evidence indicates that the P53 codon 72 polymorphism can modify risk of certain cancers such as prostate cancer, lung cancer, bladder cancer, head and neck cancer, cervix cancer, and non-melanoma skin cancer [9].

During the last decade, various individual studies have been carried out to examine the association between p53 Arg72Pro polymorphism and thyroid cancer risk,

Corresponding Author:

Dr. Mohammad Forat Yazdi

Department of Internal Medicine, Shahid Sadoughi University of Medical Sciences, Yazd, Iran.

Email: mohammad.foratyazdi@gmail.com 
but the results from these studies were controversial. Meta-analysis is a powerful way to identify the association of genetic polymorphisms with cancer risk. Therefore, the current meta-analysis was conducted to clarify whether there is an association between p53 Arg72Pro polymorphism and thyroid cancer risk.

\section{Materials and Methods}

\section{Publication search}

The relevant case-control studies on the association between p53 codon 72 polymorphism and thyrod cancer risk published before October 1, 2016 were identified by searching databases of PubMed, EMBASE, Web of Science and Google Scholar. The extracted publications were limited to English language and conducted on human subjects. The search keywords used were as follows: "p53 gene," "TP53," "Arg72Pro," "Codon 72," "polymorphism," "thyroid neoplasm," "thyroid cancer," and "thyroid carcinoma". We evaluated all the retrieved studies by reading the title and abstract. Any article matching the keywords was retrieved without any restriction. Reference lists of the retrieved articles were also screened for original papers.

\section{Inclusion and exclusion criteria}

The following inclusion criteria were used to select eligible studies for the meta-analysis: (1) with case-control or cohort design; (2) studies assessing the association between p53 Arg72Pro polymorphism and thyroid cancer risk; (3) presented genotype frequency of GG, GC, and CC in both cases and controls. Review articles, case reports, letters, reviews, and those without definite information of genotypes were excluded.

\section{Data extraction}

Two investigators independently conducted the search for qualified publications according to the study criteria and extracted the required data from the eligible publications. The extracted data included first authors, year of publication, country of origin, ethnicity, total number of cases and controls, cancer type, and allele and genotype frequency in cases and controls. The disagreements were resolved by discussion and consulting a third senior author.

\section{Statistical Analyses}

To estimate the risk of thyroid cancer [odds ratio (OR) and $95 \%$ confidence interval (CI)], we recorded genotype frequency from each study. The effects of $\mathrm{G}$ vs. C (allele model), CC vs. GG (homozygote genotypes), $\mathrm{GC}$ vs. GG (heterozygote genotypes), $\mathrm{CC}+\mathrm{GC}$ vs. GG (dominant model), and CC vs. GC+GG (recessive model) were evaluated for all studies. A subgroup analysis was conducted to evaluate the effect of $\mathrm{p} 53$ codon 72 polymorphism on the susceptibility to thyroid cancer in different populations (Asian, Caucasian, and Brazilian Mixed). Heterogeneity between studies was performed by Q statistic and I2 test. A p value less than 0.1 indicated the presence of heterogeneity [10]. The pooled ORs were calculated with the fixed-effects model based on
Mantel-Haenszel method when no significant between study heterogeneity was indicated; the random effects model using DerSimonian-Laird method was employed when obvious heterogeneity was present [11]. HardyWeinberg equilibrium (HWE) in controls of each study was checked by a chi-square test for goodness of fit. Potential publication bias was estimated by using Begg's funnel plots and Egger's test. Egger's test $p$ value of $<$ 0.05 was considered to be statistically significant [12]. All the statistical analyses were performed by comprehensive meta-analysis (CMA) V2.0 software (Biostat, USA). All tests were two-sided, and the $\mathrm{P}$ values of $<0.05$ were considered statistically significant.

\section{Results}

\section{Study characteristic}

In total, 21 studies relevant to the role of p53 codon 72 polymorphism on thyroid cancer susceptibility were identified through the literature search and selection according to the inclusion criteria. Of these, 9 papers were excluded because of obvious irrelevance by reading the titles and abstracts. Finally, a total of 12 case-control studies with a total of 2062 cases and 3927 controls were included in the meta-analysis. The characteristics of included studies were summarized in Table 1. All the eligible studies were written in English. The populations came from different countries, including China, India, Iran, Brazil, Russia, Kingdom of Saudi Arabia (KSA), turkey, and Germany. There were 4 studies of Caucasian descendants [13-16], 4 studies of Asian descendants [17$20]$ and 4 studies were conducted Brazilian mixed ethnic [16, 21-23]. In addition, the distribution of genotypes in the controls was consistent with HWE in all studies, except three studies $(\mathrm{P}<0.05)[18,21,24]$.

\section{Meta-analysis results}

Our results showed that the $\mathrm{p} 53$ codon 72 polymorphism was associated with thyroid cancer risk in the overall populations only under homozygote (CC vs. GG: $\mathrm{OR}=1.18,95 \% \mathrm{CI} 1.12-3.05, \mathrm{P}=0.01)$ and recessive genetic model (CC vs. GC+GG: OR $=1.73,95 \%$ CI 1.16 $2.59, \mathrm{P}=0.007)$ (Table 2, Figure 1).

\section{Stratified analysis by ethnicity and histological type}

The stratified analyses in Asians, Caucasians and mixed were carried out according to the ethnicity of individual case-control studies. The pooled ORs indicated that the P53 codon 72 variant genotypes were not significantly associated with the development of thyroids in Asians (G vs. C: $\mathrm{OR}=0.79,95 \%$ CI $0.55-1.14, \mathrm{P}=0.21$, GC vs. GG: $\mathrm{OR}=1.18,95 \%$ CI $0.98-1.42, \mathrm{P}=0.06, \mathrm{CC}$ vs. GG: $\mathrm{OR}=1.52,95 \%$ CI $0.80-2.88, \mathrm{P}=0.19, \mathrm{CC}+\mathrm{GC}$ vs. $\mathrm{GG}$ : $\mathrm{OR}=1.26,95 \% \mathrm{CI} 0.87-1.83, \mathrm{P}=0.21, \mathrm{CC}$ vs. $\mathrm{GC}+\mathrm{GG}$ : $\mathrm{OR}=1.46,95 \%$ CI $0.87-2.46, \mathrm{P}=0.15)$, Caucasians (G vs. $\mathrm{C}$ : $\mathrm{OR}=0.91,95 \%$ CI $0.51-1.64, \mathrm{P}=0.77, \mathrm{GC}$ vs. GG: $\mathrm{OR}=0.84,95 \%$ CI $0.48-1.45, \mathrm{P}=0.53, \mathrm{CC}$ vs. GG: $\mathrm{OR}=1.79,95 \%$ CI $0.67-4.77, \mathrm{P}=0.24, \mathrm{CC}+\mathrm{GC}$ vs. $\mathrm{GG}: \mathrm{OR}=0.93,95 \%$ CI $0.49-1.76, \mathrm{P}=0.82, \mathrm{CC}$ vs. $\mathrm{GC}+\mathrm{GG}: \mathrm{OR}=1.86,95 \% \mathrm{CI} 0.72-4.84, \mathrm{P}=0.19)$ and 
A

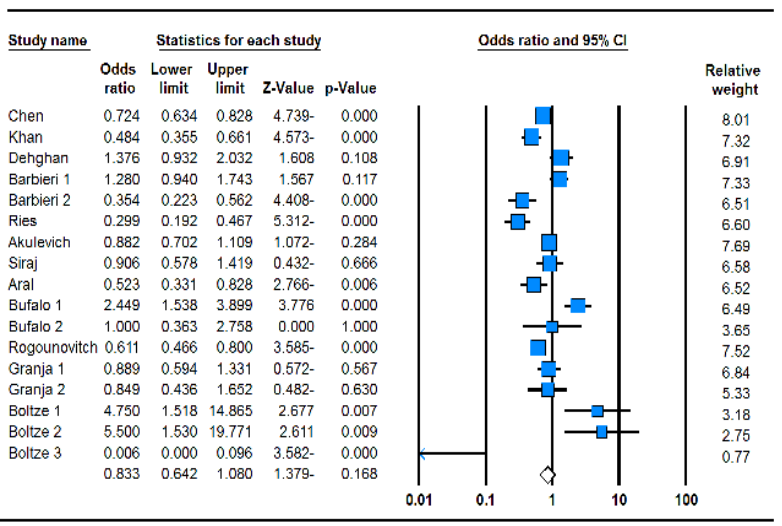

C

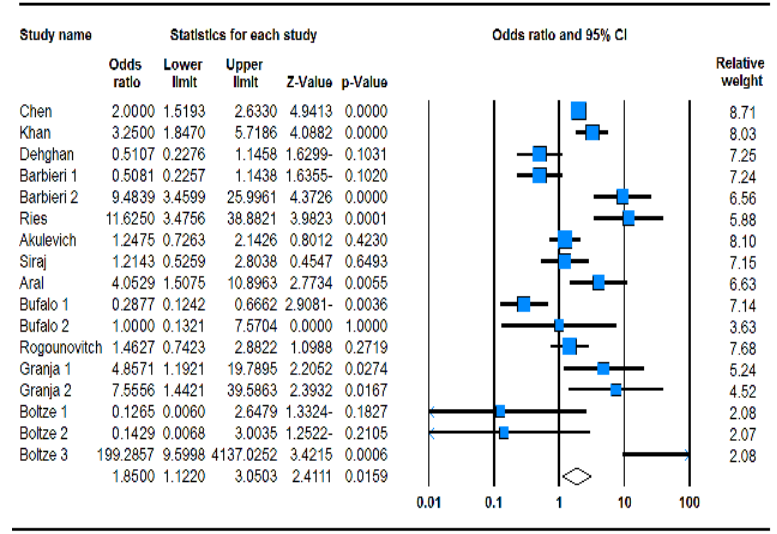

B

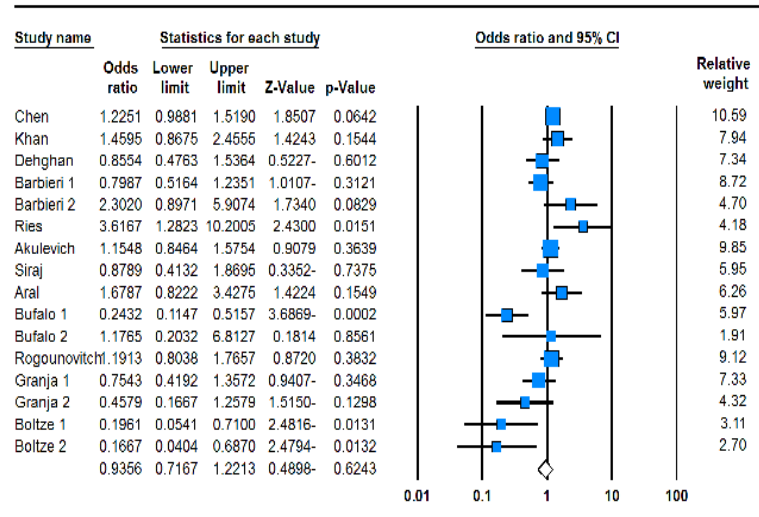

D

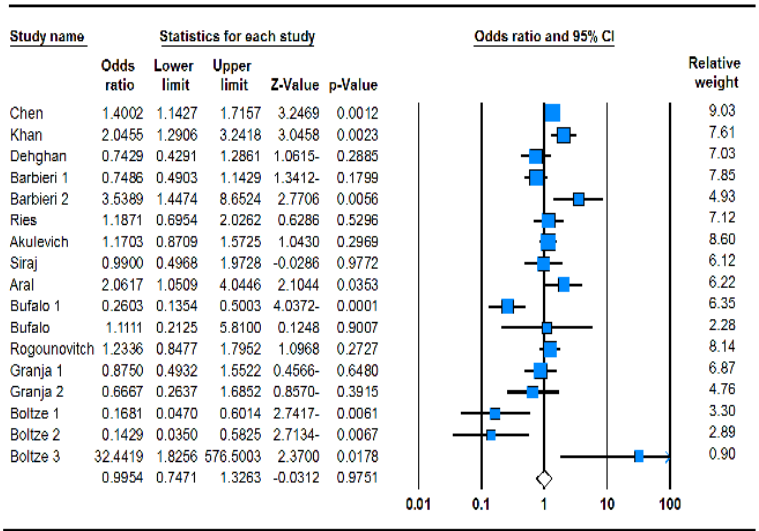

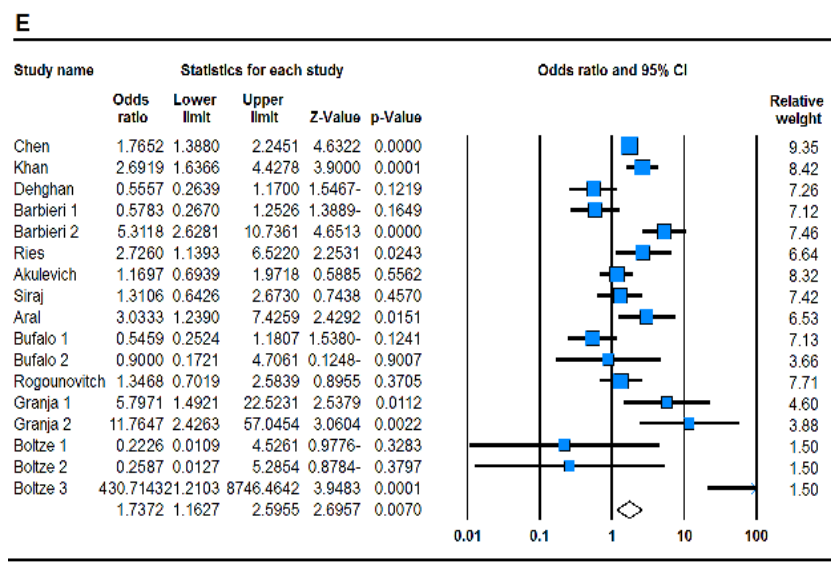

Figure 1. Forest Plots (Random Effect) Showed Significant association between P53 Codon $72 \mathrm{G}>\mathrm{C}$ Polymorphism and Thyroid Cancer Risk. A, G vs. C; B, CC vs. GG; C, GC vs. GG; D, CC+GC vs. GG; and E, CC vs. GC+GG; Results of individual and summary OR estimates and $95 \%$ CI of each study were shown. Horizontal lines represented $95 \% \mathrm{CI}$, and dotted vertical lines represent the value of the summary OR.

mixed (G vs. C: $\mathrm{OR}=0.81,95 \%$ CI $0.45-1.45, \mathrm{P}=0.48$, $\mathrm{GC}$ vs. $\mathrm{GG}: \mathrm{OR}=0.88,95 \% \mathrm{CI} 0.48-1.62, \mathrm{P}=0.69, \mathrm{CC}$ vs. $\mathrm{GG}: \mathrm{OR}=2.42,95 \% \mathrm{CI} 0.66-8.78, \mathrm{P}=0.17, \mathrm{CC}+\mathrm{GC}$ vs. $\mathrm{GG}$ : $\mathrm{OR}=0.87,95 \%$ CI $0.51-1.47, \mathrm{P}=0.61, \mathrm{CC}$ vs. $\mathrm{GC}+\mathrm{GG}: \mathrm{OR}=2.11,95 \% \mathrm{CI}$ 0.84-5.30, $\mathrm{P}=0.11)($ Table 2). In addition, subgroup analysis by histological type (PTC, DTC, MTC, FTC) showed that TP53 Arg72Pro polymorphism was not associated with risks of different types of thyroid carcinoma (Data not shown).

\section{Heterogeneity and sensitivity analyses}

Moderate heterogeneity across the studies of the p53 Arg72Pro polymorphism was found in this meta-analysis ( $\mathrm{P}=0.094$, allele $\mathrm{C}$ vs. allele $\mathrm{G} ; \mathrm{P}=0.082$, $\mathrm{GC}$ vs. $\mathrm{GG})$. We assessed the source of the heterogeneity by subgroup analyses based on ethnicity and source of control and found that Parhar et al. was the main contributor to the obvious heterogeneity. When this comparison was removed, there was a substantial increase in homogeneity across the studies $(\mathrm{P}=0.609 ; \mathrm{P}=0.548$, respectively). Subsequent sensitivity analysis was conducted to check the influence 


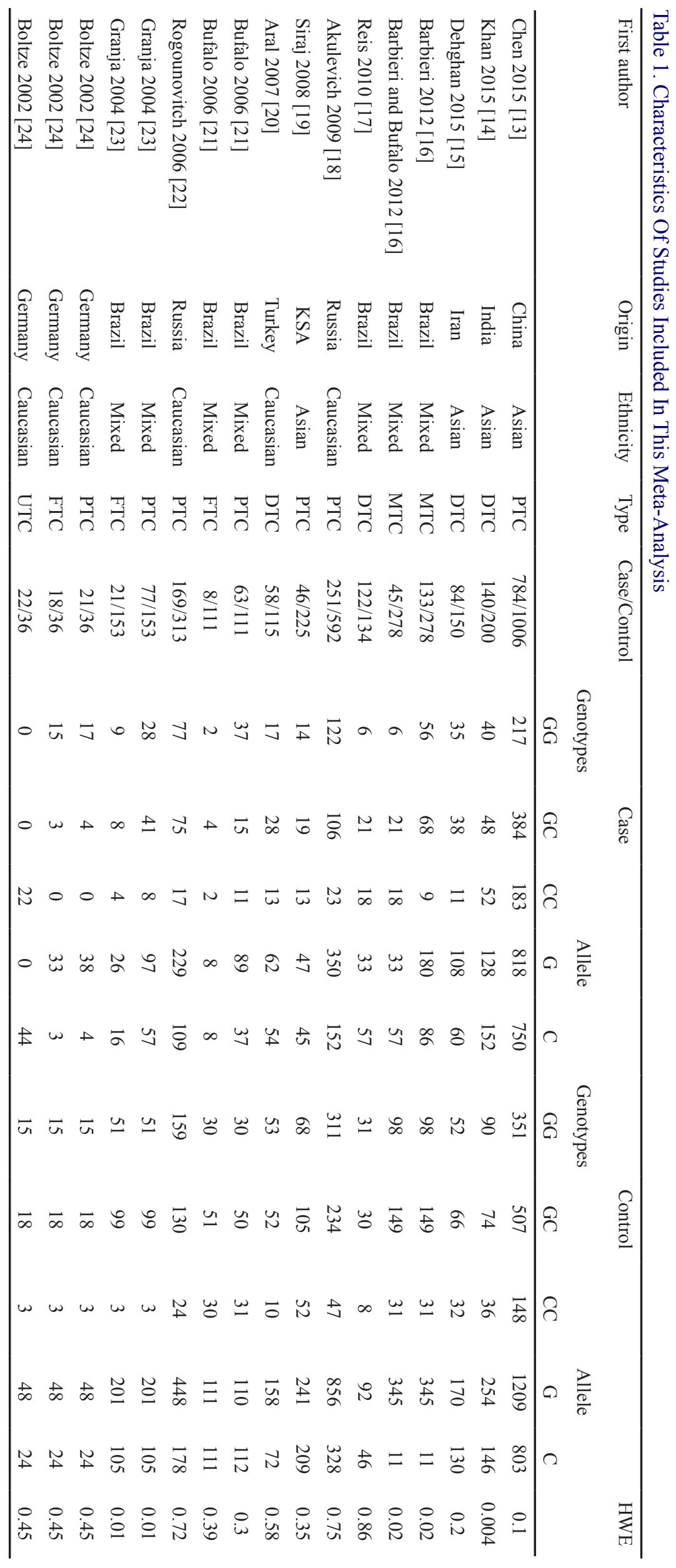


Table 2. Results of Meta-Analysis for P53 Codon 72 Polymorphism and Thyroid Cancer Risk

\begin{tabular}{|c|c|c|c|c|c|c|c|}
\hline & Genetic model & Type of model & Heterogeneity & & dds rati & & \\
\hline & & & $\mathrm{I}^{2}(\%)$ & $\mathrm{P}_{\mathrm{H}}$ & OR & $95 \% \mathrm{CI}$ & $\mathrm{P}_{\mathrm{OR}}$ \\
\hline \multicolumn{8}{|l|}{ Overall } \\
\hline & G vs. C & Randomized & 86 & $\leq 0.001$ & 0.83 & $0.64-1.08$ & 0.16 \\
\hline & GC vs. GG & Randomized & 68 & $\leq 0.001$ & 0.93 & $0.71-1.22$ & 0.62 \\
\hline & $\mathrm{CC}$ vs. GG & Randomized & 81 & $\leq 0.001$ & 1.85 & $1.12-3.05$ & 0.01 \\
\hline & $\mathrm{CC}+\mathrm{GC}$ vs. GG & Randomized & 77 & $\leq 0.001$ & 0.99 & $0.74-1.32$ & 0.97 \\
\hline & $\mathrm{CC}$ vs. $\mathrm{GC}+\mathrm{GG}$ & Randomized & 77 & $\leq 0.001$ & 1.73 & $1.16-2.59$ & 0.007 \\
\hline \multicolumn{8}{|l|}{ Ethnicity } \\
\hline \multicolumn{8}{|l|}{ Caucasian } \\
\hline & G vs. C & Randomized & 86 & $\leq 0.001$ & 0.91 & $0.51-1.64$ & 0.77 \\
\hline & GC vs. GG & Randomized & 73 & 0.004 & 0.84 & $0.48-1.45$ & 0.53 \\
\hline & CC vs. GG & Randomized & 74 & 0.002 & 1.79 & $0.67-4.77$ & 0.24 \\
\hline & $\mathrm{CC}+\mathrm{GC}$ vs. GG & Randomized & 80 & $\leq 0.001$ & 0.93 & $0.49-1.76$ & 0.82 \\
\hline & $\mathrm{CC}$ vs. $\mathrm{GC}+\mathrm{GG}$ & Randomized & 74 & 0.001 & 1.86 & $0.72-4.84$ & 0.19 \\
\hline \multicolumn{8}{|l|}{ Asian } \\
\hline & G vs. C & Randomized & 83 & $\leq 0.001$ & 0.79 & $0.55-1.14$ & 0.21 \\
\hline & GC vs. GG & Fixed & 0 & 0.47 & 1.18 & $0.98-1.42$ & 0.06 \\
\hline & CC vs. GG & Randomized & 80 & 0.002 & 1.52 & $0.80-2.88$ & 0.19 \\
\hline & $\mathrm{CC}+\mathrm{GC}$ vs. GG & Randomized & 65 & 0.03 & 1.26 & $0.87-1.83$ & 0.21 \\
\hline & $\mathrm{CC}$ vs. $\mathrm{GC}+\mathrm{GG}$ & Randomized & 76 & 0.006 & 1.46 & $0.87-2.46$ & 0.15 \\
\hline \multicolumn{8}{|l|}{ Brazilian Mixed } \\
\hline & G vs. C & Randomized & 90 & $\leq 0.001$ & 0.81 & $0.45-1.45$ & 0.48 \\
\hline & GC vs. GG & Randomized & 74 & 0.001 & 0.88 & $0.48-1.62$ & 0.69 \\
\hline & CC vs. GG & Randomized & 88 & $\leq 0.001$ & 2.42 & $0.66-8.78$ & 0.17 \\
\hline & $\mathrm{CC}+\mathrm{GC}$ vs. $\mathrm{GG}$ & Randomized & 75 & $\leq 0.001$ & 0.87 & $0.51-1.47$ & 0.61 \\
\hline & $\mathrm{CC}$ vs. $\mathrm{GC}+\mathrm{GG}$ & Randomized & 83 & $\leq 0.001$ & 2.11 & $0.84-5.30$ & 0.11 \\
\hline
\end{tabular}
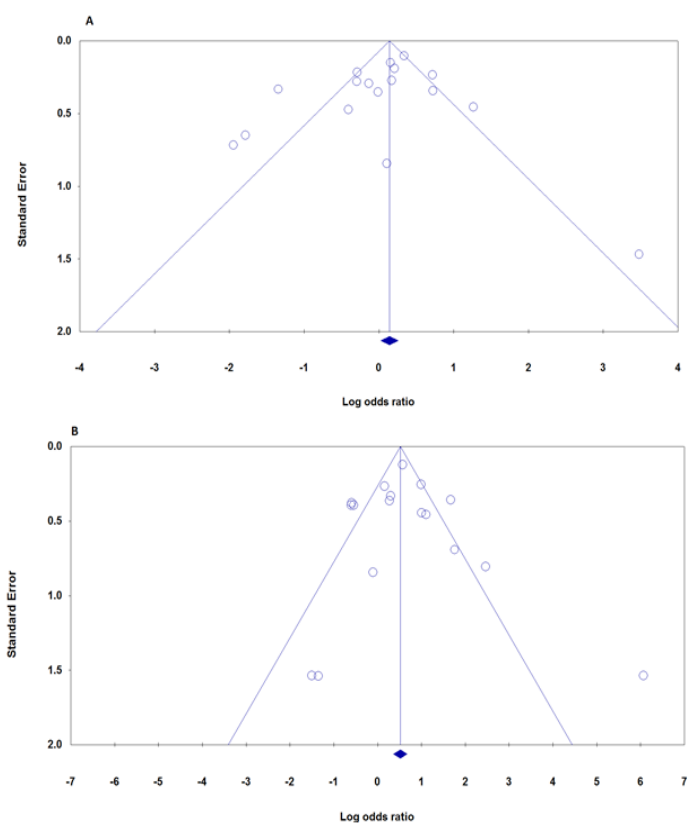

Figure 2. Funnel Plot Analysis for Publication Bias in the Studies of the Meta Analysis on the association between P53 Codon 72 Polymorphism and Thyroid Cancer Risk (A, CC+GC vs. GG; Begg's test, P, 0.387; B, CC vs. GC+GG; Begg's test, P, 0.773). of each study on the pooled ORs by omitting each study, one at a time. The sensitivity analysis indicated that no single study influenced the pooled ORs qualitatively (data not shown), suggesting the stability of our overall results.

\section{Sensitivity analysis}

Sensitivity analysis was performed to assess the impact of individual studies on the pooled ORs. The results revealed that no single study affected the summary ORs significantly (data not shown), suggesting the reliability of the results in our meta-analysis.

\section{Evaluation of heterogeneity}

In order to test the heterogeneity among the studies, $Q$ test and I2 statistics were employed. Heterogeneity was observed in all the studied genetic models. Thus, random effect model was used to synthesize the data (Table 2).

\section{Publication bias}

Publication bias was determined by performing Egger's test and Begg's test. The symmetrical funnel plot suggested that there existed no obvious publication bias, which was further confirmed in the Egger's test $(\mathrm{CC}+\mathrm{GC}$ vs. GG: Begg's test: $\mathrm{P}=0.387$; Egger's test: $\mathrm{P}=0.278$, $\mathrm{CC}$ vs. $\mathrm{GC}+\mathrm{GG}$ : Begg's test: $\mathrm{P}=0.773$; Egger's test: $\mathrm{P}$ $=0.790$ Figure 2 ). 


\section{Discussion}

The $\mathrm{p} 53$ protein is a very important part of genome integrity, and the joint effects of $\mathrm{p} 53$ and other proteins can promote the cell cycle. Since the dysfunction of cell cycle can result in the development of cancer, genetic mutations in the p 53 gene are suggested to alter host's susceptibility to thyroid cancer [25]. There are several common single nucleotide polymorphisms in the $\mathrm{p} 53$ gene, and P53 codon $11,47,72$, and 248 polymorphisms are the three most studied ones [26]. p53 codon 72 polymorphism is a $G$ to $\mathrm{C}$ substitution at exon 6 , which further results in an amino acid change from Arg to Pro [27].

To get a more precise assessment of the association between p53 codon $72 \mathrm{G}>\mathrm{C}$ polymorphism and thyroid cancer risk, we performed the present meta-analysis. Twelve studies with a total of 2062 cases and 3927 controls were finally included into the met analysis. Overall, there was obvious association between p53 codon $72 \mathrm{G}>\mathrm{C}$ polymorphism and thyroid cancer risk under homozygote (CC vs. GG: $\mathrm{OR}=1.18,95 \%$ CI 1.12-3.05, $\mathrm{P}=0.01$ ) and recessive model (CC vs. $\mathrm{GC}+\mathrm{GG}$ : $\mathrm{OR}=1.73,95 \%$ CI 1.16-2.59, $\mathrm{P}=0.007$ ) (Table 1). Subgroup analysis according to ethnicity detected no significant association in Asians, Caucasians and mixed Brazilian. Thus, the meta-analysis suggests that there is no obvious association between XRCC1 Arg194Trp polymorphism and prostate cancer risk.

In the present meta-analysis, we only assessed the association between p53 codon $72 \mathrm{G}>\mathrm{C}$ polymorphism and thyroid cancer risk and there was a significant association between p53 codon $72 \mathrm{G}>\mathrm{C}$ polymorphism and thyroid cancer. However, the associations of other $\mathrm{p} 53$ polymorphisms with thyroid cancer risk are not assessed in the present meta-analysis, and those associations need further studies.

Obviously, there were moderate to high level heterogeneity. From the subgroups analysis, we found that ethnicity might not be the source of heterogeneity (Table 2). When we deleted the study which was not according to HWE any more, the heterogeneity of all genetic models was not decreased and the results of all five genetic models were not affected. This further indicated that deviations in HWE might not be one source of heterogeneity.

There were some limitations of our meta-analysis. Firstly, there were only 12 studies with a total of 2,062 subjects that were finally included into the meta-analysis. The limited number of studies may increase the risk of bias in the meta-analysis, especially in the subgroup analysis by race. Thus, more studies with large samples are needed. Secondly, the eligibility criteria for inclusion of cases and controls were different between the included studies. The controls in most studies were selected from non-cancer individuals, while the controls in other studies were from healthy individuals. Third, due to the unavailability of other detailed information, we have not conduct stratified analysis based on some factors such as gender and age which may influence the results. Finally, in the current meta-analysis we have focused only on the one single SNP on thyroid cancer risk rather than combined effects of $\mathrm{p} 53$ other well-known polymorphisms, which could help to improve a precise estimation of the roles of p53 polymorphism in the development of thyroid cancer. Therefore, studies with good design are needed in the future, and ORs adjusted for other confounding factors need reporting.

In summary, current meta-analysis results indicated that the p53 codon $72 \mathrm{G}>\mathrm{C}$ polymorphism may be associated with thyroid cancer risk. However, more studies with large sample size are needed to further assess the associations.

\section{Funding}

No specific funding was obtained to support the conduct of this study.

\section{Conflict of Interest}

The authors declare that they have no conflict of interest.

\section{Ethical approval}

This article does not contain any studies with human participants or animals performed by any of the authors.

\section{Acknowledgments}

Our sincere thanks to Dr. Mohammad Hasan Sheikhha who provided advise on the statistical methods used within this paper.

\section{References}

1. Pellegriti G, Frasca F, Regalbuto C, Squatrito S, Vigneri $\mathrm{R}$. Worldwide increasing incidence of thyroid cancer: update on epidemiology and risk factors. Journal of cancer epidemiology. 2013;2013:965212.

2. Davies L, Welch HG. Increasing incidence of thyroid cancer in the United States, 1973-2002. Jama. 2006;295(18):2164-7.

3. American Cancer Society. What are the key statistics about thyroid cancer? (accessed January 29, 2015). URL http:// www.cancer.org/cancer/ thyroidcancer/detailedguide/ thyroid-cancer-key-statistics. 2014, [

4. Ferlay J, Steliarova-Foucher E, Lortet-Tieulent J, Rosso S, Coebergh JW, Comber H, et al. Cancer incidence and mortality patterns in Europe: estimates for 40 countries in 2012. European journal of cancer (Oxford, England : 1990). 2013;49(6):1374-403.

5. Rahbari R, Zhang L, Kebebew E. Thyroid cancer gender disparity. Future oncology (London, England). 2010;6(11):1771-9.

6. Wang F, Wang P, Wang B, Fu ZJ, Yuan Y, Yan SL, et al. Association between TP53 Arg72Pro polymorphism and thyroid carcinoma risk. Tumour biology : the journal of the International Society for Oncodevelopmental Biology and Medicine. 2014;35(3):2723-8.

7. Lajin B, Alachkar A, Alhaj SA. Duplex Detection of TP53 Arg72Pro and 16 bp Del/Ins Polymorphisms by a Simple Optimized PCR-RFLP Method. North American journal of medical sciences. 2012;4(5):212-5.

8. Hou J, Gu Y, Hou W, Wu S, Lou Y, Yang W, et al. P53 codon 72 polymorphism, human papillomavirus infection, and their interaction to oral carcinoma susceptibility. BMC genetics. 2015;16:72. 
9. K. LTHN. The Role of Thiamine in Wilson's Disease: Possible Genetic and Cellular Signaling Mechanisms. Journal of Molecular and Genetic Medicine 2013;;07((03).).

10. Huedo-Medina TB, Sanchez-Meca J, Marin-Martinez F, Botella J. Assessing heterogeneity in meta-analysis: Q statistic or I2 index? Psychological methods. 2006;11(2):193-206.

11. DerSimonian R, Kacker R. Random-effects model for meta-analysis of clinical trials: an update. Contemporary clinical trials. 2007;28(2):105-14.

12. Song F, Khan KS, Dinnes J, Sutton AJ. Asymmetric funnel plots and publication bias in meta-analyses of diagnostic accuracy. International journal of epidemiology. 2002;31(1):88-95.

13. Akulevich NM SV, Rogounovitch TI, Drozd VM, Lushnikov EF, Ivanov VK, et al. . Polymorphisms of DNA damage response genes in radiation-related and sporadic papillary thyroid carcinoma. Endocrinol Relat Cancer. 2009; . 491-503. p.

14. Aral C ÇS, Özışık G, Massoumilary S, Sönmez O, Akkiprik $\mathrm{M}$, et al. . The association of $\mathrm{p} 53$ codon 72 polymorphism with thyroid cancer in Turkish patients. . Marmara Medical Journal. 2007;20((1);):1-5.

15. Rogounovitch TI, Saenko VA, Ashizawa K, Sedliarou IA, Namba H, Abrosimov AY, et al. TP53 codon 72 polymorphism in radiation-associated human papillary thyroid cancer. Oncology reports. 2006;15(4):949-56.

16. Boltze C, Roessner A, Landt O, Szibor R, Peters B, Schneider-Stock R. Homozygous proline at codon 72 of p53 as a potential risk factor favoring the development of undifferentiated thyroid carcinoma. International journal of oncology. 2002;21(5):1151-4.

17. Chen P, Sun R, Pu Y, Bai P, Yuan F, Liang Y, et al. Pri-Mir-34b/C and Tp-53 Polymorphisms are Associated With The Susceptibility of Papillary Thyroid Carcinoma: A Case-Control Study. Medicine. 2015;94(38):e1536.

18. Khan MS, Pandith AA, Masoodi SR, Khan SH, Rather TA, Andrabi KI, et al. Significant association of TP53 Arg72Pro polymorphism in susceptibility to differentiated thyroid cancer. Cancer biomarkers : section A of Disease markers. 2015;15(4):459-65.

19. Dehghan R HFM, Pouladi N, Babaei E, Montazeri V, Fakhrjoo A et al. Association of P53 (-16ins-Pro) Haplotype with the Decreased Risk of Differentiated Thyroid Carcinoma in Iranian-Azeri Patients. . Pathology \& Oncology Research. 2014; . 449-54. p.

20. Siraj AK A-RM, Ibrahim M, Siddiqui K, Al-Dayel F, Al- Sanea O, et al. Rad52 polymorphisms contribute to the development of papillary thyroid cancer susceptibility in middle eastern population. . J Endocrinol Investig $2008 ; ; 31:: 893-9$.

21. Barbieri RB, Bufalo NE, Cunha LL, Assumpcao LV, Maciel RM, Cerutti JM, et al. Genes of detoxification are important modulators of hereditary medullary thyroid carcinoma risk. Clinical endocrinology. 2013;79(2):288-93.

22. Reis AA, Silva DM, Curado MP, da Cruz AD. Involvement of CYP1A1, GST, 72TP53 polymorphisms in the pathogenesis of thyroid nodules. Genetics and molecular research : GMR. 2010;9(4):2222-9.

23. Bufalo NE, Leite JL, Guilhen AC, Morari EC, Granja F, Assumpcao LV, et al. Smoking and susceptibility to thyroid cancer: an inverse association with CYP1A1 allelic variants. Endocrine-related cancer. 2006;13(4):1185-93.

24. Granja F, Morari J, Morari EC, Correa LA, Assumpcao LV, Ward LS. Proline homozygosity in codon 72 of p53 is a factor of susceptibility for thyroid cancer. Cancer letters. 2004;210(2):151-7.
25. Collavin L, Lunardi A, Del Sal G. p53-family proteins and their regulators: hubs and spokes in tumor suppression. Cell death and differentiation. 2010;17(6):901-11.

26. Almeida BC, Kleine JP, Camargo-Kosugi CM, Lisboa MR, Franca CN, Franca JP, et al. Analysis of polymorphisms in codons 11, 72 and 248 of TP53 in Brazilian women with breast cancer. Genetics and molecular research : GMR. 2016;15(1).

27. Neamatzadeh H, Soleimanizad R, Zare-Shehneh M, Gharibi S, Shekari A, Rahimzadeh AB. Association between p53 codon 72 (Arg72Pro) polymorphism and primary open-angle glaucoma in Iranian patients. Iranian biomedical journal. 2015;19(1):51-6.

This work is licensed under a Creative Commons AttributionNon Commercial 4.0 International License. 